\title{
Erratum to: Characterization of Dendritic \\ Microstructure, Intermetallic Phases, and Hardness of Directionally Solidified Al-Mg and Al-Mg-Si Alloys
}

\author{
CRYSTOPHER BRITO, THIAGO A. COSTA, TALITA A. VIDA, FELIPE BERTELLI, \\ NOÉ CHEUNG, JOSÉ EDUARDO SPINELLI, and AMAURI GARCIA
}

DOI: $10.1007 / \mathrm{s} 11661-015-3012-3$

(C) The Minerals, Metals \& Materials Society and ASM International 2015

\section{Erratum to: METALLURGICAL AND MATERIALS TRANSACTIONS A DOI: 10.1007/s11661-015-2967-4}

THE authors regret that numerical errors were identified in Figures 10(a, right graph) and (b, right graph) and 12. In the calculation of the growth rate of the Al-3.0 wt pet Ni alloy, a mistake has been found. The corrected figures and their respective legends are reproduced below. The error does not change the main discussions and conclusions of the work. In addition, a sentence containing the discussion associated with Figure 12 has been rewritten as follows.

As can be observed in Figure 12, the BK model roughly matches the experimental tendency of evolution of the secondary dendrite arm spacing with the growth rate.

CRYSTOPHER BRITO, THIAGO A. COSTA, and TALITA A. VIDA, Ph.D. Students, FELIPE BERTELLI, Researcher, NOÉ CHEUNG and AMAURI GARCIA, Professors, are with the Department of Manufacturing and Materials Engineering, University of Campinas, UNICAMP, PO Box 6122, Campinas, SP 13083-970, Brazil. JOSÉ EDUARDO SPINELLI, Professor, is with the Department of Materials Engineering, Federal University of São Carlos UFSCar, São Carlos, São Paulo 13565-905, Brazil. Contact e-mail: spinelli@ufscar.br

The online version of the original article can be found under doi: 10.1007/s11661-015-2967-4.

Article published online June 16, 2015 

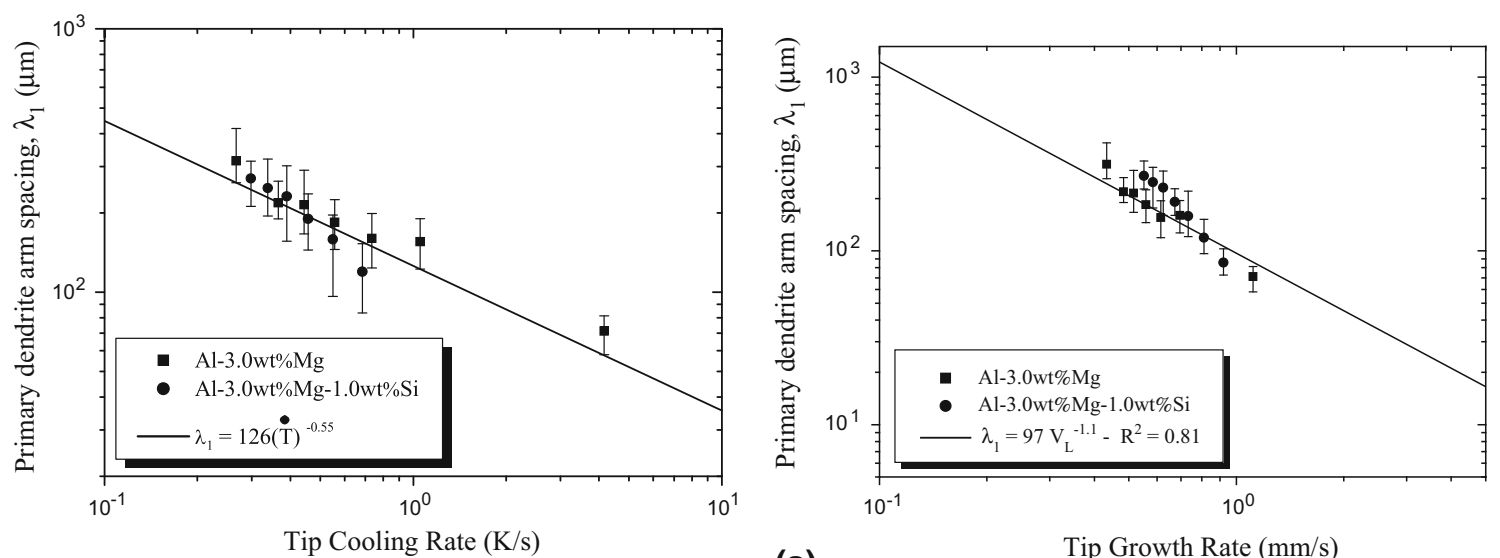

(a)

Tip Growth Rate $(\mathrm{mm} / \mathrm{s})$
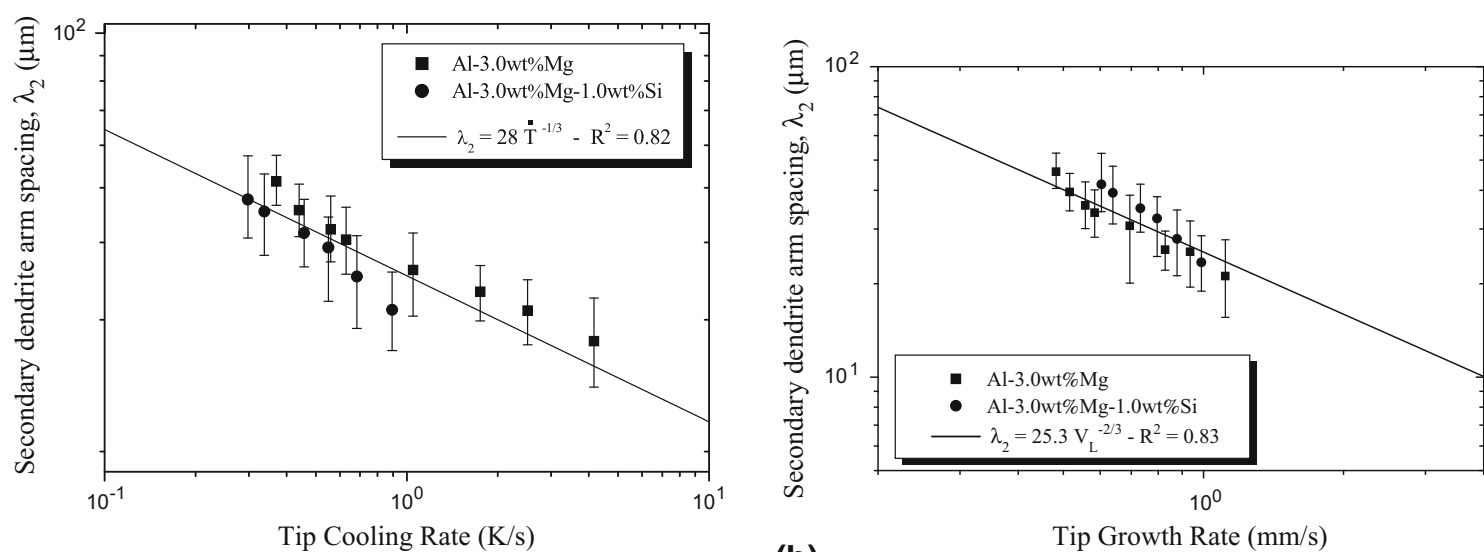

(b)

Tip Growth Rate $(\mathrm{mm} / \mathrm{s})$

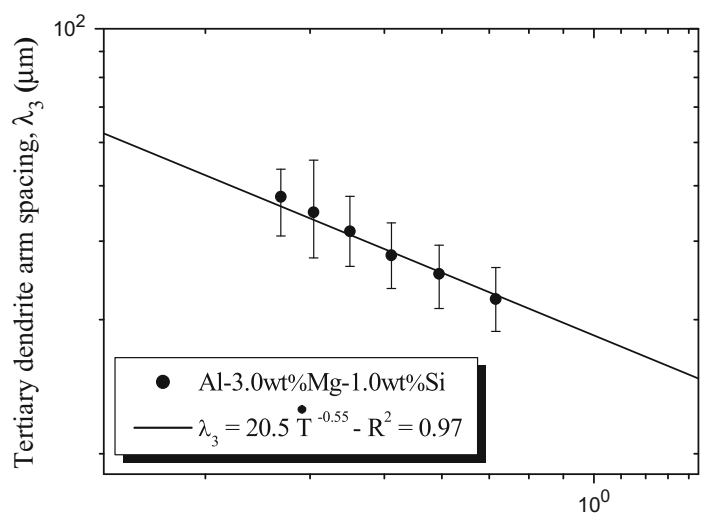

Tip Cooling rate $(\mathrm{K} / \mathrm{s})$

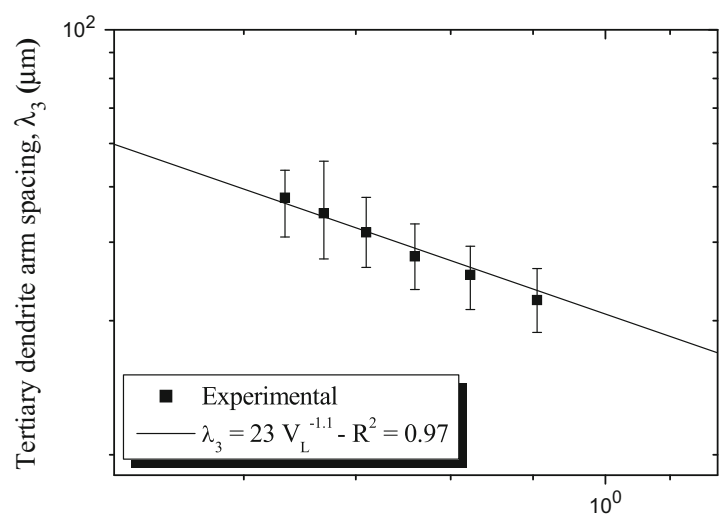

Tip Growth Rate $(\mathrm{mm} / \mathrm{s})$

(c)

Fig. 10 - Correlations between dendrite arm spacings and solidification thermal parameters: $(a) \lambda_{1}$ evolution as a function of tip cooling rate and tip growth rate and $(b) \lambda_{2}$ evolution as a function of tip cooling rate and tip growth rate; and $(c)$ evolution of the tertiary dendritic spacing, $\lambda_{3}$, for the ternary Al-3.0 wt pet Mg-1.0 wt pet Si alloy as a function of tip cooling rate and tip growth rate. 


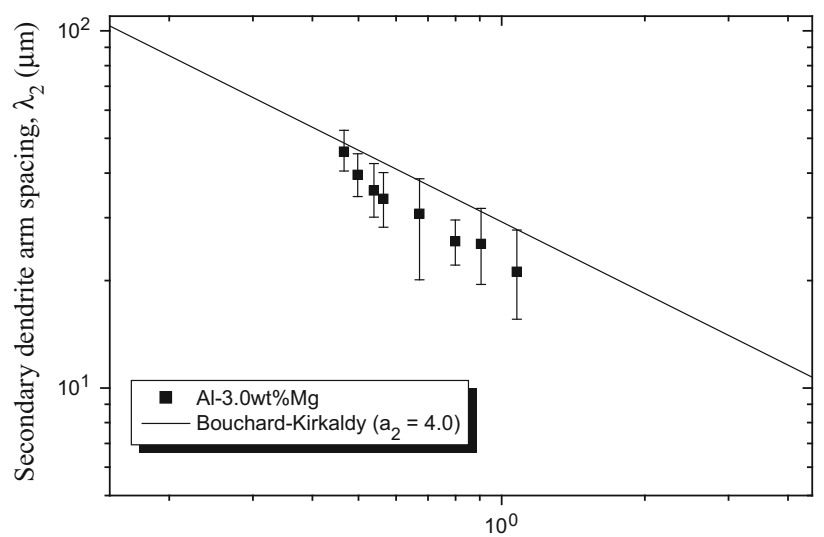

Tip Growth Rate (mm/s)

Fig. 12-Comparison of experimental and theoretical $\lambda_{2}$ as a function of $V_{\mathrm{L}}$ for the Al-3.0 wt pet $\mathrm{Mg}$ alloy. 